\title{
O yoga como prática de áskesis
}

\author{
Ernesto Grillo Rabello' \\ Fernando Hiromi Yonezawa² \\ Ana Paula Figueiredo Louzada ${ }^{3}$
}

\section{RESUMO}

Este ensaio tem por objetivo estabelecer uma reflexão de como a prática do yoga pode constituir-se como áskesis, como prática ascética, no sentido dado por Foucault, com base nas antigas práticas gregas do cuidado de si. Não pretendemos traçar simples semelhanças, visando igualar o yoga e as práticas antigas gregas, mas mostrar como a prática do yoga pode apresentar elementos de áskesis, tal como caracterizada por Foucault. Assim, veremos que o yoga pode produzir um contato do sujeito consigo e constituir uma estilística para a produção de transformações na vida. Diante da relevância que o yoga tem adquirido atualmente como prática corporal, destacamos a importância de refletir quais modos éticos e práticos junto à vida a prática pode suscitar.

Palavras-chave: Yoga. Áskesis. Subjetividade. Práticas corporais.

1 Mestre em Psicologia Institucional pela Universidade Federal do Espírito Santo (UFES). Vitória/Espírito Santo, Brasil. E-mail: rabello.ernesto@gmail.com

2 Doutor em Psicologia. pós-doutorando do Programa de Pós-graduação em Psicologia Institucional da Universidade Federal do Espírito Santo. E-mail: fefoyo@yahoo.com.br

3 Doutora em Educação pela Universidade Federal do Espírito Santo e professora adjunta do Departamento de Psicologia da mesma Universidade. E-mail: paulalouzada27@gmail.com

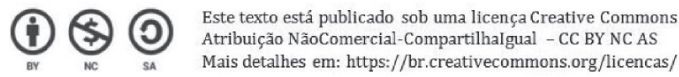




\section{Yoga as an áskesis practice}

\section{ABSTRACT}

This essay aims to establish a reflection about how the yoga practice can be constitutive of an áskesis, in the sense given by Foucault on the basis of ancient Greek practices of care of the self. We do not intend to make simple approximations or equate yoga and ancient Greek practices, but show that the practice of yoga can present elements of áskesis, as characterized by Foucault. Thus, we will see that yoga can induce a contact of the subject with oneself and constitute a stylistic for the production of transformations in one's life. Given the relevance that yoga as a body practice has acquired nowadays, it is also important to reflect what kind of ethics and practice in life the practice raises.

Keywords: Yoga. Áskesis. Subjectivity. Body practices.

\section{El yoga como practica de áskesis}

\section{RESUMEN}

Este ensayo tiene por objetivo establecer una reflexión de cómo un cierto modo de practicar yoga puede constituirse como áskesis, en el sentido dado por Foucault con base en las antiguas practicas griegas del cuidado de sí. No pretendemos hacer aproximaciones simples o tampoco igualar el yoga y las practicas antiguas griegas, sino mostrar que la practica del yoga presenta elementos de la áskesis, tal como se caracteriza por Foucault. Así, veremos que el yoga recupera un contacto del sujeto consigo mismo y constituye una estilística para la producción de transformaciones en la vida. Ante la relevancia que el yoga como práctica corporal ha adquirido actualmente, emerge la importancia también de reflejar qué tipo de ética y practica junto a la vida él suscita.

Palabras clave: Yoga. Áskesis. Subjetividad. Practicas corporales. 


\section{O YOGA, UM YOGA}

O yoga vem sendo desenvolvido na Índia há milhares de anos e suas origens são desconhecidas. Historicamente, os primeiros registros de posições de yoga vêm de dois sítios arqueológicos da região do Vale do Rio Indo, região norte da Índia e sul do Paquistão, atual Caxemira: Mohenjo-Dharo e Harappa. Em um dos registros, Pashupati, o senhor dos animais, antiga representação do deus hindu Shiva, é ilustrado sentado em uma posição de meditação.

Ainda não há consenso sobre a história destas civilizações, tampouco sobre as datas de seu apogeu e declínio. O fato é que Harappa e Mohenjo-Dharo eram civilizações consideradas urbanas, que desenvolveram arte, comércio e arquitetura avançadas, antes mesmo das civilizações egípcia e mesopotâmica (DANIÉLOU, 1989). Por serem sítios arqueológicos recentes, as pesquisas seguem em andamento e as hipóteses sobre os modos de vida das civilizações do Vale do Indo são muitas. De todo modo, é consenso entre diferentes autores que algumas técnicas do yoga antigo se tornaram uma prática social neste contexto, apesar de serem muito anteriores a ele. Daniélou (1989) aponta que as técnicas do yoga compunham, juntamente com muitos rituais, as bases do Shivaísmo antigo, religião animista de culto às forças da natureza e da vida, desenvolvida pelas civilizações dravidianas.

Notadamente, a busca pelas origens do yoga pode facilmente levar à confusão e ao desentendimento. Swami Satyananda Saraswati (2008), ao comentar sobre os sastras, textos hinduístas nos quais se encontram os registros das práticas antigas, aponta que a principal falha concernente aos referidos textos é que eles não podem ser fielmente datados por ser difícil dizer quem influenciou quem e qual texto veio antes.

Mais ainda, uma escritura não fixa de forma alguma a data de um sistema filosófico; uma escritura pode ter sido redigida centenas de anos depois da formulação, desenvolvimento e proliferação de uma filosofia específica. (SARASWATI, 2008, p. 8, tradução nossa).

Não poderíamos, pois, pretender uma busca da origem exata do yoga, já que as lacunas históricas são expressivas e o volume de textos é enorme. No subcontinente indiano muitos e diferentes estilos de yoga foram sendo produzidos e se mantém coexistindo, sem que um exclua o outro. Assim, esta pequena introdução histórica pretende apenas trazer alguns traços constitutivos do yoga, para minimamente localizar o leitor leigo. Doravante, compreendamos sucintamente como se deu a inserção do yoga na cultura ocidental.

Singleton (2010) demonstra que, em nossa era, na virada do século XIX para o século XX, a Europa experimentava uma expansão de diferentes métodos de ginástica corporal. Nestes métodos o movimento do corpo ganhava destaque com a finalidade de tratar enfermidades e prevenir doenças. Posteriormente incorporados aos sistemas escolares e militares ingleses, os "métodos de ginástica e cuidados pelo movimento" chegaram à Índia e motivaram o interesse pelas antigas disciplinas corporais já existentes neste país, 
como fonte de preparação atlética. Assim sendo, o yoga passou a ser adaptado à preparação militar e incorporado nas práticas educacionais indianas. $\mathrm{O}$ fato de diferentes textos antigos da Índia abordarem o yoga como excelente disciplina para cuidado com o corpo despertou o interesse pela prática de asanas (posturas corporais), pranayamas (técnicas respiratórias) e outras técnicas. Singleton (2010) aponta ainda como algumas organizações, como a Associação Cristã de Jovens (YMCA), se apropriaram das técnicas antigas para seus programas de educação física. Posteriormente, diferentes mestres indianos, incentivados pelo governo de seu país, iniciaram apresentações públicas de técnicas de yoga na Europa e nos Estados Unidos, visando a disseminação de seus trabalhos e a promoção da Índia no cenário mundial.

Os processos de disseminação do yoga nos séculos XX e XXI produziram divergências e diversos modos de ensino da prática. Em distintos países do mundo inteiro são muitas linhagens e sistemas de práticas de yoga, cada uma com propostas próprias, por vezes opostas, derivadas das mesclas produzidas ao longo do tempo. Esclarecemos que, por linhagens, dizemos de escolas de yoga que seguem instruções específicas, passadas de mestre para discípulo ao longo do tempo, sem grandes alterações; temos, como exemplo, a linhagem de Hatha Kundalini Yoga de Swami Satyananda Saraswati, discípulo de Sivananda; e a linhagem de Ashtanga Vinyasa Yoga, de Sri K. Pattabi Jois, discípulo de Krishnamacharya. Por sistemas dizemos de métodos de ensino contemporâneos, criados com abordagens tomadas de diferentes linhagens, como o Sistema Shivam Yoga, de Arnaldo de Almeida, o Swasthya Yoga, de DeRose, e o Kundalini Yoga, de Yogi Bhajan. Fica claro que é impossível, portanto, abordar 'o' yoga como unidade que englobe todos os diferentes modos de praticar. Pensamos que o artigo definido 'o' permanece neste texto por pura conveniência lingüística, já que falamos sempre de 'um' yoga, ou seja, todo sistema ou linhagem tem uma história específica e implica um modo de praticar e de ver o mundo. Não pretendemos, portanto, que o presente texto defenda um único modo de como o yoga pode ser abordado, já que, novamente, realçamos que a perspectiva colocada aqui é apenas uma dentre muitas outras passíveis de serem elaboradas.

Assim sendo, o yoga, hoje, se configura como uma prática corporal contemporânea de cuidado como muitas outras, tais como o Método de Conscientização do Movimento através da dança, o Método Pilates, a Capoeira, algumas artes marciais, e além. Um signo da importância que o yoga tem adquirido é o fato de que, no Brasil, ainda neste ano, o Ministério da Saúde emitiu a portaria 145/2017, a qual inclui o yoga no rol das práticas a serem oferecidas publicamente dentro da Política Nacional de Práticas Integrativas e Complementares (PICs) do Sistema Único de Saúde (SUS), juntamente com tecnologias como acupuntura, fitoterapia, arteterapia, biodança, danças circulares, entre outras.

Atualmente, qualquer pessoa que busque informações sobre yoga, tanto em livros como na internet, bem como qualquer um que pretenda fazer 'aulas experimentais' de diferentes linhagens, tende a se deparar com um campo extremamente vasto, polívoco e, por vezes, confuso. Em uma breve busca pelo vocábulo 'yoga' na internet, juntamente com uma página da Wikipédia explicando o termo, vê-se páginas patrocinadas de diferentes linhagens explicando o que seria a prática antiga segundo sua visão e promovendo 
propagandas de seus núcleos. Há até sugestões de aplicativos para celular que oferecem aulas; também aparecem na pesquisa sugestões de vídeos de todo tipo, separando práticas para diferentes níveis, com sugestões de práticas específicas para perda de peso, realçando alguns benefícios como diminuição de ansiedade e estresse, e até se referindo ao yoga como "treino de força e flexibilidade que funciona melhor que academia".

Diante desse contexto de difusão em que o yoga se insere, se torna importante refletir sobre a sua prática e como ela pode ser entendida como produtora de transformações nos praticantes. A partir dos trabalhos de Foucault buscamos pensar como as práticas corporais do yoga podem se constituir como exercícios de liberdade, engendrando novas relações do praticante consigo. Afirmamos, pois, que o cultivo de uma prática como o yoga pode ser um exercício de produção de uma vida com aberturas de autonomia. Buscamos, nos textos de Michel Foucault sobre a noção de práticas de si, alguns elementos que auxiliem este exercício do pensamento, afirmando a possibilidade da prática de yoga se configurar como áskesis. Com isso não pretendemos realizar aproximações ingênuas entre as práticas gregas e as relativas ao yoga, mas elaborar uma reflexão que se norteie pela pergunta: como o yoga pode se constituir como áskesis e, sendo assim, como prática com potencial de produzir transformações nos praticantes?

\section{Uma prática, um cultivo}

Vamos explorar agora como uma prática de yoga pode se conduzir. Convidamos o leitor a se deixar conduzir por um sadhana, uma prática de Shivam Yoga, exercitando uma imersão imaginária, mas como se o observador fosse aquilo mesmo que se observa. As técnicas que serão abordadas aqui são apenas algumas simples possibilidades dentre muitas disponíveis e a escolha pela condução segundo a prática do Shivam Yoga se justifica pelo fato de um dos autores deste trabalho ser também praticante e instrutor desta escola de yoga.

Primeiramente chega-se ao local do sadhana. Imaginemos que seja em um parque público, em um espaço coberto e sem paredes. É noite. A sensação de amplitude e tranqüilidade o envolve logo na chegada, seja pelo toque do vento na pele, seja pelas árvores ao redor, seja pelo canto dos pássaros. Por mais que o dia tivesse sido intenso, cheio de atividades e atribulações, aquele lugar te convida a uma parada, a um silenciamento.

Outras pessoas chegam também, amigos, conhecidos ou pessoas que usualmente você só encontra ali. Aos poucos vocês se cumprimentam, se abraçam e conversam sobre o dia que passou, ou sobre o que têm vivido. Logo chega também o instrutor que vai guiar a prática naquela noite e, entre abraços e breves conversas, os incensos são acesos. O aroma, carregado pela brisa da noite, flutua pelo espaço aberto. Pouco a pouco todos se posicionam no tablado de cimento, estendendo seus tecidos ou desenrolando suas esteiras. Todos se sentam. Você fecha os olhos, respira fundo e silencia. Sentado em posição de meditação, com as pernas cruzadas, você se estica, leva o dorso de uma mão sobre a palma da outra, solta os ombros, verticaliza a coluna, a fim de facilitar os fluxos de energia e dissolve as 
tensões na testa e nos maxilares. Você respira fundo, pensa no dia que passou e se percebe ali, naquele momento e naquele lugar. Você fecha os olhos e a prática se inicia.

Dharana, concentração mental. O instrutor convida ao silêncio. Inicialmente, sua percepção se dissolve entre os sons do parque, os sons longínquos da cidade, o aroma dos incensos, os pensamentos e as imagens, vestígios dos encontros do dia. Pouco a pouco você se concentra, focando a atenção em sua própria respiração. $\mathrm{O}$ instrutor o convida a aprofundá-la pelas narinas, sentindo o ar alcançar a região do baixo ventre. É difícil ampliar a respiração e você percebe como as tarefas do dia-a-dia estão sendo vividas por você com um fluxo respiratório superficial, localizado no alto do tórax. Você se esforça, tentando ampliar a respiração e, ao fazê-lo, você percebe como a respiração profunda reduz sua ansiedade, assentando os pensamentos e o corpo ao solo. Você se concentra e, lentamente, os pensamentos e as imagens do dia vão ganhando menos atenção e importância, assim como os sons ao redor: você se sente silenciado e presente. Você sente uma desaceleração e acessa um outro ritmo. Você permanece exercitando a concentração mental.

Puja, transmissões de energia e agradecimento. $\mathrm{O}$ instrutor o convida a levar as mãos espalmadas uma contra a outra, com os dedos para cima diante do peito, em namaskar mudra, e em seguida solicita que você imagine ondas de luz azul celeste, vindas do Universo, que se aproximam e passam a te envolver. Esta nuvem de luz se integra ao seu campo energético e ao corpo físico e você se sente leve, vivo e vibrante. Em seguida, o instrutor convida que você expanda esta nuvem de energia, envolvendo todo o local da prática e os demais praticantes. Você passa a se sentir integrado ao ambiente e com os demais yoguins, praticantes, percebendo que não está só. Estas transmissões de energia são lentamente ampliadas, enviadas aos demais praticantes que não estão presentes, enviadas a pessoas que você ama e com as quais você se importa, enviadas aos mestres que transmitem os ensinamentos do yoga. Você é tomado por sensações de gratidão pelas suas relações e por uma forte conexão com os demais seres que o rodeiam. Você percebe que faz parte de uma grande rede, que envolve tanto os demais praticantes daquele local quanto todos os outros seres vivos.

Pranayama, exercícios respiratórios. O instrutor o convida a mudar de posição, levando as mãos em jñana mudra sobre os joelhos, mantendo as mãos abertas para cima, unindo apenas as pontas dos dedos indicador e polegar. Neste momento suas costas começam a doer e você rapidamente percebe como é difícil executar uma posição aparentemente tão simples como se sentar ao solo com as pernas cruzadas. Surgem imagens que lembram como você se acomoda normalmente nos lugares, seja em cadeiras duras ou em sofás espaçosos e você percebe, assim, como é sua postura no cotidiano: encurvada e desatenta. 'Preciso observar isso durante os dias', você pensa. Então se movimenta um pouco, buscando aliviar o desconforto, e retorna sua atenção à fala do instrutor.

Ele inicia um exercício respiratório, surya bheda kumbhaka com bandhas, a respiração completa, com retenções e com exercícios de energização. Inicialmente, você inicia o exercício inspirando profundamente, preenchendo completamente os pulmões de ar, de baixo para cima. Com os pulmões cheios, você retém a respiração, inclina a cabeça para trás e para baixo e pressiona com a ponta da língua o palato mole, uma região rugosa no 
céu da boca. Em seguida, como orienta o instrutor, você retorna a cabeça no prolongamento da coluna, engole a saliva e expira, lenta e profundamente, expulsando ativamente o ar dos pulmões, relaxando o tórax e contraindo o abdômen. Com os pulmões vazios, você retém a respiração e contrai os esfíncteres da uretra e do ânus, elevando o assoalho pélvico, e contraindo também a musculatura do baixo ventre e do abdômen, para dentro e para o alto. Você retém a respiração, executando as contrações pelo maior tempo possível e, precisando inspirar, relaxa a musculatura solicitada, iniciando um novo ciclo do exercício.

Você segue a execução do pranayama e o instrutor realça em seu discurso os efeitos da técnica, "trabalhando a concentração mental, aumentando a capacidade respiratória e ativando os centros de energia, os chakras, ampliando a absorção e a circulação de prana, a energia vital". Você se mantém concentrado executando a técnica, atentando-se ao ritmo e ao som de sua respiração. Você começa a perceber também que há musculaturas sendo exigidas que você usualmente não utiliza, aprofundando a sensação de conexão entre a respiração e diferentes camadas musculares. A contração do baixo ventre massageia os órgãos internos do abdômen e sensações de movimento e fluidez surgem nesta região, substituindo uma sensação de estagnação que vinha te acompanhando ao longo do dia. Após algumas repetições, o instrutor encerra a execução da técnica.

Anga asanas, posições corporais. O instrutor pede que você abra os olhos e alongue suas pernas à frente, desfazendo a posição de meditação. Você movimenta as pernas e os pés, ainda se acostumando com o retorno do sentido da visão. Seus olhos estão atentos. O instrutor solicita um movimento de rotação dos pés, trabalhando as articulações dos tornozelos. Você se atenta à execução e consegue perceber com precisão a musculatura solicitada para executar o movimento, tamanha é a dimensão perceptiva corporal produzida pelas técnicas anteriores.

De asana em asana, a prática flui. O instrutor vai lentamente executando diferentes posições enquanto você e seus colegas vão acompanhando os movimentos. As posições são variadas e suas execuções cadenciadas vão ampliando sua percepção corporal. Uma posição de alongamento posterior de todo o corpo, por exemplo, o leva a perceber a estreita relação entre as tensões nas partes posteriores das pernas, das costas e do pescoço. Ao descer o tronco para frente, com as pernas alongadas, segurando seus pés, você percebe fluxos de energia que vêm desde os calcanhares até a nuca. Estes fluxos (ou os seus cortes) são percebidos por você de diferentes maneiras ao longo da prática: ondas de calor, pulsação, formigamento e dormência, sensações de leveza, de desbloqueio e de abertura. Enquanto você executa a técnica, estas sensações correspondem, a nível físico, ao afrouxamento de tendões, ao alongamento de músculos, à liberação de fluxos orgânicos variados e à ampliação dos fluxos sangüíneos e de oxigênio. O instrutor lembra, "respire profundamente na posição e, ao expirar, retire todo o ar dos pulmões e avance, melhorando seu domínio da posição e alongando a musculatura posterior do corpo". Você respira na posição e, por mais que ela possa ser dolorida ou incômoda, você se concentra nas sensações produzidas pela técnica junto de sua respiração e avança a cada expiração. Imagens de seu dia a dia surgem na experiência e você percebe como tem se conduzido 
no cotidiano. Ao localizar as tensões incômodas no corpo, você também as localiza em sua vida, percebendo quais relações as têm produzido.

Lentamente a prática avança e mais asanas são realizados. Há uma ampliação cognitiva e sensorial que acontece e você passa a perceber os limites do corpo. Gradativamente, você busca ampliar estes limites através de uma respiração lenta e profunda. Sempre ao expirar você sente que avança um pouco. Você percebe que só é possível avançar gradualmente, através de um longo caminho, e o próprio instrutor o conduz a esta percepção: "avance lentamente, ampliando seus limites, sem se comparar aos outros; vivencie seus processos com paciência consigo mesmo". Às vezes você é tomado pela ansiedade de alcançar um estado avançado da posição que, muitas vezes, é demonstrado pela execução do instrutor e também pela execução de outros praticantes. Entretanto, o próprio instrutor realça: "avance em seu tempo, não pressione a si mesmo, perceba a fluidez do processo em andamento". Uma atenção à processualidade se produz e você se acalma.

Você sente os tendões sendo esticados, os músculos se alongando e, aos poucos, sente sua soltura e a ampliação de suas possibilidades de movimento. Movimentos que até pouco tempo atrás lhe eram impossíveis agora se tornam fáceis e isto produz novas possibilidades de ação em seu cotidiano. É possível perceber também que, com a concentração na exalação da respiração, fica mais fácil ampliar a flexibilidade muscular e também mental, sendo que uma produz a outra de modo circular. Quer dizer, você percebe que, se ficamos mentalmente desesperados com a rigidez de certas regiões do corpo com que chegamos à prática, ou se ficamos preocupados com a sensação de estiramento, pior é. Entretanto, se respiramos fundo e, ao expirar, buscamos usufruir do difícil processo de ir alongando as articulações e os músculos mais tensionados, facilmente sentimos os exercícios com mais leveza e percebemos uma expansão das possibilidades do corpo. Músculos, vísceras, tendões, ossos, sensações, emoções e eventuais pensamentos são percebidos em conjunto durante a prática dos asanas. Estica daqui, contrai dali, e a prática segue. Em posições que trabalham força e equilíbrio você percebe quais membros e músculos são solicitados e consegue levar a atenção para estes pontos específicos, concentrando a percepção no corpo. A maioria dos exercícios do yoga são isométricos, ou seja, implicam contrações musculares em uma só posição por um período longo de tempo, o que aumenta a resistência muscular e a sensação de força prolongada, sem perda de flexibilidade. Nestas posições, são os músculos mais profundos que são solicitados, bem próximos aos ossos e órgãos, os quais garantem sustentação, consistência e segurança. Estas características são percebidas por você como um forte sentido de 'força interna' e correspondem ao modo como o próprio corpo se percebe e se sente em si mesmo e no espaço.

Yoganidra, relaxamento final. Depois de diversas posições serem praticadas, o instrutor o guia para outro momento da sessão. Deitado ao solo, com os pés separados, as mãos afastadas do tronco com as palmas voltadas para cima, você fecha os olhos. A respiração está profunda e vigorosa, efeito das técnicas anteriores. Você está suando. Sua pulsação está forte e alcança até as pontas dos dedos dos pés e das mãos. Você inspira, sentindo a força da pulsação, e expira, se soltando ao solo. O instrutor conduz a técnica de relaxamento final, solicitando que a cada expiração você se entregue mais ao solo. 
Todos estão deitados ao solo e o instrutor solicita a visualização de uma nuvem de energia azul celeste, vinda do Universo em sua direção. Esta nuvem de energia começa a envolver seus pés, se expande por pernas, envolve quadril e baixo ventre, dissolvendo as tensões e o cansaço nas pernas. Você sente que lentamente suas pernas relaxam e descansam e um leve fluxo de energia passa a percorrer seu corpo. $\mathrm{O}$ instrutor continua a condução da técnica, levando-o a visualizar esta nuvem de luz envolvendo cada vez mais partes do corpo: quadril, costas, abdômen, tórax, órgãos internos, ombros e braços, pescoço e cabeça. Os pensamentos cessam, o coração se acalma, os sons e odores se distanciam, você se vê completamente envolvido por esta energia azul e se encontra em um estado de profundo relaxamento. "Perceba a integração entre os diferentes níveis de seu ser; perceba as conexões entre você e os demais seres do Universo; medite nesta conexão e relaxe profundamente".

Lentamente, o instrutor vai convocando todos a recobrarem a atenção, conectando-se aos sons do parque, à respiração profunda, passando a língua sobre os lábios, movimentando dedos de mãos e pés, se massageando e se acariciando. Você vira de lado e sente o corpo muito pesado e é difícil levantar, como se estivesse saindo de um sono profundo. Todos se sentam ao solo em posição de meditação. O pranava 'Om' é entoado por todos e, por fim, o instrutor o convida a se atentar aos efeitos da prática, da execução do conjunto de técnicas; você se sente leve, tranqüilo e sereno; o instrutor pede que esta energia seja expandida para todos os seres, beneficiando-os, ampliando os efeitos destas técnicas; levando as aprendizagens para o restante de seus dias, vocês abrem os olhos e se cumprimentam todos. O sadhana termina.

Mesmo após o instrutor finalizar a prática as pessoas continuam sentadas por algum tempo, sentindo seus efeitos. Algumas com os olhos fechados, ainda em estado meditativo, outras executando asanas aleatórios que queiram, outras começam a conversar. Você se sente muito tranqüilo e sereno, desligado de todos os resquícios do dia acelerado que passou. Você se sente bem em si mesmo. Devagar você levanta e começa a encontrar os amigos praticantes, trocando abraços e conversas sobre o andar da vida. Alguém chama a todos para se sentarem novamente a compartilhar um chá. Outro alguém traz um pão feito em casa para a roda. E ali vocês começam a conversar sobre como foi a prática, sobre como vocês se sentiram, e as experiências vão sendo compartilhadas. Os mais variados assuntos começam a circular, os sorrisos desinteressados aparecem e uma forte sensação de conexão com o grupo se faz presente. O parque, ainda em silêncio, os acolhe. Você, por fim, se levanta e vai para casa. No dia seguinte você acorda bem, se sentindo renovado e busca, a partir da memória do dia anterior presente no corpo, manter o estado alcançado de serenidade e tranquilidade. Você percebe que este estado transforma seu modo de se relacionar com as pessoas ao seu redor, produzindo conexões não mais baseadas em padrões rígidos de ação. Você se torna mais flexível, você se abre a escutar os outros, se percebe mais solidário e menos egoísta; mas também se sente forte para se posicionar frente aos desafios que você encontra, seja resistindo às demandas dos outros, seja demarcando seu posicionamento frente a determinadas questões. Você percebe os efeitos proporcionados pela prática, vê como novos modos de olhar e viver as relações estão se produzindo e sente vontade de permanecer no caminho, praticando. 
Encerramos aqui a proposta de imersão em um sadhana. É interessante observar que o discurso do instrutor no momento da prática é um guia que auxilia o yoguin na experiência. Ao executar uma técnica aliada a um discurso como "avance, exercite a coragem", o instrutor implica uma qualidade ao exercício, que deixa de ser meramente físico e passa a se tornar o exercício de uma virtude para a própria realidade. A nosso ver é preciso, para isto, que o instrutor esteja alinhado com um darshana, uma perspectiva. Portanto, o instrutor não é um mero executor e corretor de técnicas, mas também opera uma função de mestria, no sentido que Foucault emprega ao termo: o de ser um cuidador do cuidado, o de ser um guia de condutas. Sigamos, então, buscando pensar de que maneira uma prática de yoga, conduzida segundo esta estilística de prática descrita acima, pode ser entendida como prática de áskesis.

\section{A áskesis grega e a áskesis yoguin}

Há um consenso entre diferentes autores (FOUCAULT, 2006; DANIÉLOU, 1989; SARASWATI, 2013; HADOT, 1999) de que, na região da Europa e da Ásia, diferentes técnicas de auto-formação foram desenvolvidas e se mesclaram ao longo dos milênios. Michel Foucault (2006) questiona se essas práticas antigas, mágico-religiosas, não teriam sido transpostas, decantadas e transformadas, ao longo do tempo, se tornando as práticas filosóficas e espirituais gregas estudadas por ele. Foucault (2011) deixa claro, inclusive, que a ocupação com a existência através de técnicas de si não é uma invenção da filosofia grega. As diferentes maneiras elaboradas de ser e de conduzir os aspectos da existência, ou seja, uma preocupação ético-estética com a vida, fez parte de muitas formações sociais ditas 'arcaicas'. Para o autor há a marca, nestas sociedades, de

um trabalho contínuo e sempre renovado de enformação, pelo menos tanto quanto a forma que esses mesmos homens procuraram dar aos deuses, aos templos ou à canção das palavras. Essa estética é um objeto histórico essencial que não se deve esquecer (FOUCAULT, 2011, p. 141).

Com efeito, encontramos na definição de "práticas de si" de Foucault um terreno comum que permite olhar para diferentes práticas antigas, da Índia ou da Europa: o fato de visarem uma transformação do modo de ser do praticante, através de diferentes operações, buscando atingir um determinado estado de sabedoria, felicidade, pureza ou imortalidade, como já apontado anteriormente nas palavras do próprio Foucault (2006). Estas "operações" são, para o autor, aquilo que compõe o corpus das práticas ascéticas,

o conjunto mais ou menos coordenado de exercícios disponíveis, recomendados, até mesmo obrigatórios, ou pelo menos utilizáveis pelos indivíduos em um sistema moral, filosófico e religioso, a fim de atingirem um certo objetivo espiritual definido (FOUCAULT, 2006, p. 505). 
Foucault (2006) aponta que os termos "ascese" ou "ascetismo" têm conotações de atitude de renúncia, mortificação, e se liga a experiências que buscam uma suposta salvação ou o perdão divino. $\mathrm{O}$ autor demonstra que esta conotação negativa do termo surge após a incorporação das técnicas ascéticas antigas no interior do cristianismo, que as passa a utilizar como meio de expiação dos pecados da carne e como regras às quais todos devem se submeter. No período grego e romano, por outro lado, víamos técnicas de controle que visavam meditações muito precisas, preparando o sujeito para lidar com os acontecimentos da vida, sendo essas regras de caráter facultativo. Era o caso de se sentar com fome diante de um banquete e resistir ao impulso de comer: meditação sobre a riqueza e a pobreza, preparação para um possível infortúnio e sua superação, aprendizado da dosagem do próprio desejo, produção de um modo de vida. Curiosamente, essa mesma prática vai ser incorporada no seio do cristianismo como exercício regrado e proibitivo, exercício de renúncia do desejo de comer, este entendido agora como 'gula', um pecado da carne, que deve ser evitado, sob pena de punição divina. Por tudo isso, Foucault demarca a diferença entre os termos áskesis e ascese.

A definição de práticas ascéticas elaborada por Foucault e evocada acima é geral e se refere tanto às ascéticas gregas antigas (que eram voluntárias) quanto à ascese cristã (obrigatória). Por "objetivo espiritual", Foucault entende uma certa transformação de si mesmo enquanto sujeito, enquanto sujeito de ação e de conhecimento, sendo a askésis a liga que une um saber e algumas práticas específicas na produção de um modo de existência.

Assim, é possível pensar que, assim como gregos e romanos abordavam suas askésis em duas dimensões, teórica (epistéme theoretiké) e prática (epistéme praktiké), também o faziam desta maneira os diferentes mestres yogues. A elaboração intuitiva das técnicas do yoga pelos antigos mestres produzia um saber sobre o corpo e o mundo que, em contrapartida, passava a alimentar a prática com prescrições e finalidades. Eis aí um primeiro ponto pelo qual a prática do yoga pode ser tomada como áskesis.

Há algumas peculiaridades destas instruções afins entre os gregos, como trazido por Foucault, e os indianos. Podemos tomar como exemplo o papel da escuta como um passo fundamental da ascese grega, quando o discípulo se punha em silêncio a escutar os discursos verdadeiros proferidos pelo mestre (FOUCAULT, 2006). No caso do yoga, era essa uma das finalidades dos sutras, os pequenos versos de fácil memorização criados pelos mestres indianos para instrução. Há inclusive uma técnica aplicada pelo mestre aos discípulos chamada yoganidra, através da qual os aprendizes eram induzidos a um estado de relaxamento profundo, entre o sono e a vigília, que facilitava a memorização dos ensinamentos.

A relação entre um mestre que guia as condutas e um discípulo que se submete a uma prática voluntária também era um aspecto recorrente nas asceses antigas. Foucault (2006) aponta que o mestre é aquele que tinha a função, na Grécia antiga, de cuidador do cuidado: o mestre ocupava a posição de um "outro" ao qual se referir e a quem buscar para que as condutas fossem guiadas apropriadamente. Este também é um tema comum na ascética yoguin. O exemplo acima, de instrução pela transmissão de sutras, é apenas uma dimensão desta relação. A presença do guru, como consultor e guia, atravessa todas 
as experiências espirituais da Índia antiga, tanto na prática do yoga quanto na prática do budismo ou de outras áskesis. Saraswati (2007), por exemplo, é sempre enfático neste ponto, apontando que algumas práticas só são possíveis de serem realizadas sob a orientação de um guru. Ele (2009) comenta que a relação guru-shishya (mestre-discípulo) é muito antiga e importantíssima na condução de uma prática espiritual, de um sadhana. Recordemos que na descrição de uma sessão de prática acima trazida já havíamos notado a diferença ético-estética produzida pelo discurso do instrutor: não se trata nunca de uma mera execução mecânica ou correção de exercícios, mas de uma condução a certos processos e estados compreendidos como capazes de ampliar a sensibilidade, pensamento e ação dos sujeitos praticantes.

Nas asceses antigas, as práticas são inseparáveis de um dado regime de verdades de um determinado sistema filosófico-espiritual. A dimensão prática da ascese é aquela que permite operar a ativação dos discursos verdadeiros proferidos pelo mestre, transformando os discursos em direção de ação. No caso do yoga, com o passar do tempo, os discursos orais indianos foram registrados e esses escritos passaram a guiar as condutas e práticas dos yoguins, praticantes de yoga. Foucault (2006) define que esta dimensão prática, nos gregos, servia à incorporação dos discursos na própria atividade do sujeito que, guiado pelo saber, transforma o conhecimento em um modo de vida. Eis a finalidade da ascese antiga grega, em sentido estrito, apontada por Foucault (2006): a produção de um êthos, uma maneira de ser e de se conduzir. Ethopoieîn, fazer um êthos, produzir um êthos, transformar o modo de existência, eis o objetivo da askésis. O conhecimento estaria presente no próprio modo de condução da vida e estaria à disposição quando necessário frente aos acontecimentos.

A prática como preparação de resposta aos acontecimentos da vida é uma finalidade-chave das asceses estudadas por Foucault. Paraskeué, preparação, "é isto que a askésis necessária a um atleta da vida visa obter" (FOUCAULT, 2006, p. 391). Esta imagem de um "atletismo para a vida" é bem interessante, tanto é que o termo gymnázein, no contexto da ascese filosófica antiga, não denota exercícios físicos, mas um exercício na realidade: dedicar-se às práticas para que elas equipem o sujeito para viver a vida, sendo a própria constituição da vida o treino (gymnázein) real. Para Foucault, as asceses gregas visavam equipar os sujeitos com um conhecimento que servisse como uma "armadura", que estivesse sempre à mão (prókheiron), um conhecimento que estivesse encarnado "nos músculos e nos nervos".

Swami Satyasangananda Saraswati (2006) elabora um conceito que nos auxilia a pensar que uma dimensão aproximada da paraskeué é presente também na prática do yoga: é a ideia de karma sannyasin. Para o autor, o yoga é uma prática que visa equipar o praticante para qualquer situação que venha se manifestar na vida, para encarar qualquer klesha, obstáculo. O karma sannyasin é o praticante que não renuncia à vida, mas que a toma como exercício constante. Como encarar a perda de um amor, uma doença na família ou uma morte próxima? "Impermanência é uma realidade áspera" (SARASWATI, 2006, p. 23, tradução nossa), aponta ele, e o yoga pode ser uma prática que auxilie o sujeito a se movimentar com equanimidade frente às mudanças. Quem persiste na prática do yoga 
por algum tempo sabe que, frente às dificuldades, o sadhana é como uma âncora que permite estabilizar os fluxos de emoções e pensamentos, por mais difícil que isto possa soar. Saraswati (2006) chama de "fundação" esta capacidade que a prática e os estudos proporcionam ao praticante. "A coisa importante, portanto, não é negar a vida, mas aceitá-la, fluir com ela, aprender com ela e desenvolver sua percepção através das experiências" (SARASWATI, 2006, p. 23, tradução nossa).

Há um termo em sânscrito que designa o aprendizado das experiências unido ao estudo do conhecimento antigo: swadhyaya, traduzido como "auto-estudo". Saraswati (2006) escreve que às vezes somos tomados por indecisões, inseguranças, descrenças e falta de inspiração. Quando isto acontecer, o mestre aponta que fugir das dificuldades não é a melhor saída: elas fazem parte da existência e com elas é preciso aprender. Nestes momentos, o importante é a prática de swadhyaya, um "auto-estudo" que leve em conta tanto os saberes acumulados sobre o yoga quanto a memória das próprias experiências anteriores com a prática, o que garante a chamada "fundação". O autor ilustra esta dimensão do yoga como uma constante preparação para a vida ao citar um trecho da conversa entre Krishna e Arjuna, no texto hindu Bhagavad Gita: "Aquele que, em meio à mais intensa atividade, se encontra em calma e paz, é o maior dos yogues e o mais sábio dos homens" (SARASWATI, 2006, p. 71, tradução nossa). Sábio ensinamento de árduo e longo aprendizado.

Nas ascéticas filosóficas antigas do ocidente, os exercícios ascéticos práticos eram basicamente exercícios de abstinência, exames do dia, pela manhã e à noite, e rememoração dos discursos, principalmente através da escrita. Não havia registro de uma instrução precisa que visasse determinar normas que devessem ser seguidas minuto a minuto. Tratava-se muito mais de exercícios que estavam à disposição dos sujeitos para livre escolha quando necessário (FOUCAULT, 2006). Transpondo esta dimensão dos exercícios ascéticos para o contexto do yoga, percebemos grandes diferenças. Por ocasião da tardia difusão da escrita na Índia, os discursos e ensinamentos eram transmitidos através de imagens e símbolos, que operavam também uma função de rememoração dos ensinamentos. No caso dos exercícios, estes são bem detalhados e visam efeitos específicos e, às vezes, são séries pré-determinadas e requerem abhyasa, constância, e tapas, austeridade. Há inclusive instruções precisas sobre qual a melhor hora do dia para executá-los. O sadhana, por exemplo, deve ser executado de preferência pela manhã, antes do sol nascer, após um banho frio e estando o praticante em jejum. Outras prescrições existem, determinando quem pode, ou não, praticar determinado exercício. Entretanto, pensamos que, por mais que haja direções e prescrições a serem seguidas, as práticas ainda são voluntárias: não dependem de um sistema moral que as pretenda universais, nem são enrijecidas a ponto de não poderem ser modificadas. Isto é importante na medida em que Foucault (2006) realça que esta dimensão de uma liberdade em relação às áskesis antigas é fundamental, visto ser um elemento que as diferenciam da posterior ascese cristã (obrigatória e prescritiva).

Ao analisar o yoga, os exercícios da áskesis tomam uma dimensão mais ampla do que os exercícios gregos e romanos por englobarem e enfatizarem uma dimensão de práticas corporais. Trazemos aqui o exemplo de uma praticante de yoga que vinha se preparando para o Exame Nacional do Ensino Médio (ENEM). Na medida em que praticava, 
ela comentava que sua capacidade de concentração para os estudos havia melhorado, bem como sua sensação de tranqüilidade para a realização da prova. Entretanto, ela conta que no dia do exame a ansiedade e o nervosismo se fizeram presentes. Quando percebeu que a ansiedade a estava atrapalhando na resolução das questões, tomou uma iniciativa inusitada: solicitou à fiscal de prova que pudesse ir ao banheiro. Lá chegando, ela conta que cobriu o chão com toalhas de papel e se apoiou sobre as mãos, executando uma posição de yoga, kakasana, a posição do corvo. A referida posição exige muita concentração para ser executada, pois é preciso se apoiar somente sobre as mãos, mantendo a respiração constante, lenta e profunda. Há também o fato de que, por ser uma posição difícil, conquistada através de sucessivas práticas, sua execução sempre remete à sensação de um desafio que pode ser superado com calma e perseverança. Estas "virtudes" que advém com a execução da técnica são reforçadas pelo instrutor ao ministrá-la, associando, no momento da instrução, uma finalidade à experiência. Para ela, no momento da prova, a técnica foi necessária para reativar um estado de concentração e tranqüilidade experimentado durante as práticas. Ela conta que lembrava, inclusive, da voz do instrutor conduzindo a execução da técnica e que, após um tempo respirando na posição, se sentiu novamente confiante e tranqüila para voltar à sala e terminar a prova. A nosso ver, este caso auxilia o pensamento de como as técnicas do yoga preparam o praticante para enfrentar alguns desafios na vida.

Ora, a experiência acima descrita nos permite pensar como o acesso ao conhecimento em uma prática ascética só é possível através da própria prática, através de um treino cultivado com constância. Vemos assim que, no yoga, além de exercícios de atenção a si e de mentalizações, a dimensão corporal adquire grande importância por trazer ao praticante técnicas e efeitos capazes de potencializar o direcionamento ético-estético da prática, reverberando diretamente em seu cotidiano. Para Foucault (2006), esta é também uma marca ética do saber e da verdade encontrada nas escolas filosóficas gregas: o modo como o saber sobre os deuses, sobre os homens e sobre o mundo podem ter efeito na maneira de agir do sujeito, em seu êthos, sua maneira de viver. O saber só é útil e desejável na medida em que é chamado a produzir o êthos. Neste sentido, convergem entre si as filosofias antigas, quando demonstram que só é possível conhecer através de uma experiência de transformação, alcançável através de uma prática. Esta afirmação é especialmente categórica na experiência com o yoga: a experiência produzida com a prática tem por efeito constituir um conhecimento passível de ser incorporado às maneiras de agir do praticante nos diversos momentos e acontecimentos da existência.

Diferentes autores (MISHRA, 2011; SARASWATI, 2008, 2013, 2007; SARASWATI, 2006) realçam que o conhecimento vivo do yoga advém pela prática. Precisamos nos deter neste ponto. O que está em jogo, aqui, é uma determinada relação com o saber. Ao se iniciar a prática do yoga, diferentes questões emergem quanto à execução das técnicas e a finalidade das mesmas. A relação com o conhecimento, com um conjunto de verdades, não se estabelece a priori, como um acúmulo intelectual de conhecimentos disponíveis, mas é ativada na medida em que se torna problema para o praticante. "Executo esta técnica, sinto isto, percebo uma diferença, o que isto implica? Como o corpus teórico e um mestre podem me auxiliar?". É justamente esta relação com o conhecimento que permite 
a transformação do conjunto de verdades em um modo de vida, pois o saber só passa a ganhar espessura corpórea através de um fazer, através da experiência.

Tal como vimos no item anterior deste texto, uma prática de yoga é inteiramente atravessada por fluxos de sensação, de percepções desconhecidas, de ampliações da sensibilidade, as quais têm por efeito produzir um novo saber ou até uma nova concepção de vida, que pode ser levada para o cotidiano: conhecimentos sobre o ritmo e amplitude respiratória em cada momento ou atividade do dia, sobre o tempo tomado para que o corpo se torne mais flexível, sobre as emoções que percorrem o espírito quando ocorre um tensionamento, sobre os efeitos comparativos entre um cotidiano ruidoso, mergulhado em trabalho incessante e uma porção de tempo dedicada ao alargamento paulatino da sensibilidade, sobre as diferenças encontradas entre focar a mente em estado relaxado e concentrá-la sob força de tensão; enfim, diversas linhas de conhecimento sobre si, sobre os órgãos do corpo, sobre a relação com o tempo, com o ambiente, com os outros. Linhas de conhecimento que, irredutíveis apenas a um momento de exercício técnico, são potencialmente levados a compor o aparato de pensamento, emoção e ação do dia-a-dia, tal como mostra a experiência da garota praticante, que lançou mão da aprendizagem obtida no yoga para enfrentar uma importante situação de exame. Este conhecimento produzido no yoga depende, portanto, de um estado de atenção sutil com as passagens afetivas e as percepções. Mishra (2011) escreve que o conhecimento do yoga vem sendo verificado e comprovado na prática por muitas gerações de yoguins até o presente e que qualquer um pode verificar esses conhecimentos, basta praticar. Assim sendo, o conhecimento não é reservado a um pequeno grupo de pessoas especiais que o detenham: ele é verificável por quem se voluntariar.

Foucault (2006) aponta que esta dimensão da relação entre conhecimento e experiência, presente na antiguidade e também em muitas áskesis orientais foi, por muito tempo, negligenciada pela tradição ocidental e esta é uma dimensão à qual, segundo ele, precisamos nos ater. Para o autor, a filosofia surge, na Grécia antiga, justamente nesta conexão entre um conhecimento que transforma e uma transformação que produz conhecimento, filosofia como áskesis, como ato, vinculada à noção de epiméleia heautôu, de práticas de si. Para Foucault, houve um momento na história do ocidente em que o conhecimento se descola da experiência, ganhando uma relativa autonomia e sobre isso nos atentaremos brevemente.

O autor (2006) destaca que, tradicionalmente, na história da filosofia, a questão do sujeito, de seu conhecimento por si mesmo, foi colocada a partir do preceito gnôthi seautón (conhece-te a ti mesmo), que se descolou da necessidade de um conjunto de práticas de si, epiméleia heautôu. A inscrição do preceito gnôthi seautón estava na entrada do oráculo de Delfos na Grécia, juntamente com outros preceitos, e correspondia a regras de prudência necessárias a quem levaria questões ao oráculo: não coloques questões demais (medèn ágan), não te comprometas com compromissos que não irás honrar (engýe) e reduza ao máximo o número de questões, cuidando de ver em ti o que tens precisão de saber (gnôthi seautón). Como reduzir então as questões, como perceber em si quais questões levar ao oráculo? Através de um conjunto de cuidados consigo, a partir de um regime de práticas, 
sob a noção de epiméleia heautôu. Foucault (2006) é bem claro neste ponto: o preceito gnôthi seautón surge no oráculo de Delfos acoplado, atrelado e até mesmo subordinado ao princípio de cuidado com as relações (epiméleia). O que aconteceu, portanto, para que o princípio do "conhece-te a ti mesmo" se descolasse do princípio mais geral do "cuida-te de ti mesmo"?

Foucault (2006) determina que, a partir da idade moderna, passou-se a assumir que o acesso à verdade se dá pelo conhecimento e tão somente o conhecimento: o gnôthi seautón poderia ser um princípio independente e suficiente em si. O autor define esta virada histórica nas relações do sujeito com o conhecimento como "momento cartesiano", atribuindo ao procedimento cartesiano a instauração de um sujeito racional que existe e conhece a verdade somente por existir, não necessitando de nenhuma transformação em seu modo de ser para se tornar sujeito de conhecimento. Haveria, no procedimento cartesiano, a instauração de uma evidência na origem do procedimento filosófico, correspondente à máxima "penso, logo existo": o pensamento se descola da ação porque, nesta perspectiva, existiria independente dela. A exaltação de um processo de pensamento descolado da necessidade de uma transformação de si é o que passa a definir esta relação com o conhecimento, em um ponto de indubitabilidade a priori da existência do sujeito. O sujeito seria evidente, porque existe só por pensar. É neste ponto que os exercícios compreendidos no conjunto do epiméleia heautôu são desqualificados e até excluídos do campo do pensamento filosófico moderno.

O que Foucault (2006) realça como importante de se ater é justamente a dimensão espiritual do conhecimento, ou seja, de que um ato de conhecimento só poderia dar acesso a um conjunto de verdades dentro de certas condições específicas, através de uma áskesis; um ato de conhecimento só seria possível se fosse preparado, acompanhado e produzido através de certa transformação do sujeito que busca conhecer. Assim sendo, perde importância, na história da filosofia ocidental, a iluminação do sujeito que conhece através de uma prática de si, o ponto em que se produz um senso de completude pelo efeito da verdade que atravessa e transforma o seu ser.

$\mathrm{Na}$ Antiguidade, portanto, a questão filosófica do acesso ao conhecimento sempre estava ligada à espiritualidade, ou seja, às "transformações necessárias no ser mesmo do sujeito que permitirão o acesso à verdade" (FOUCAULT, 2006, p. 21). O “momento cartesiano" inaugura, por sua vez, uma tradição onde

O conhecimento se abrirá simplesmente para a dimensão indefinida de um progresso cujo fim não se conhece e cujo benefício só será convertido, no curso da história, em acúmulo instituído de conhecimentos ou em benefícios psicológicos ou sociais que, no fim das contas, é tudo o que se consegue da verdade, quando foi tão difícil buscá-la (FOUCAULT, 2006, p. 24).

Ao dizer da dificuldade em buscar a verdade, Foucault se refere ao árduo labor de transformação empreendido na áskesis e é esta dificuldade que foi negligenciada e mantida sob tutela na história da filosofia, sendo a institucionalização do saber científico o ápice 
deste processo. "Essa negligência da vida filosófica possibilitou que a relação com a verdade não pudesse mais se validar e se manifestar agora a não ser na forma do saber científico" (FOUCAULT, 2011, p. 208). Assim sendo, não é mais o modo de vida e a própria vida do sujeito que faz dizer a força de uma verdade.

Se seguimos pensando as práticas ascéticas com Michel Foucault, temos que admitir que a askésis produz um êthos na medida em que o praticante se posiciona, na experiência, em relação a um conjunto de verdades tomadas para si e incorporadas através das técnicas. Numa askésis como a do yoga, é a própria vida que se faz verdadeira, uma vez que é o sujeito desta vida que se torna verdadeiro, se transformando a partir de um longo e trabaIhoso processo. Assim, o que confere verdade a um conhecimento não é sua força lógica ou sua adesão a certo número de princípios legitimadores, mas a força de transformação que suscita uma vida em meio à prática árdua e contínua. Não é uma ideia ou hipótese exterior ao sujeito que se toma como verdade, mas é o próprio sujeito que pode, ou não, ser verdadeiro, conforme haja força de verdade em sua maneira de viver. No caso do yoga como askésis, estas verdades podem ser adquiridas, por exemplo, pelo estudo dos textos antigos ou pelo discurso de condução do instrutor no momento da prática; mas também e principalmente, como mostrou a "descrição" de uma prática trazida acima, pela produção de uma nova relação do sujeito consigo, no corpo, na sensibilidade e no pensamento, ato cujo efeito é produzir um conhecimento sobre uma verdade validada no confronto com o próprio ato de seguir vivendo e experimentando sua caminhada.

\section{Askésis: yoga como transformação de si}

Vimos que a prática do yoga pode produzir novos planos de sensações e intensidades, bem como pode munir os praticantes com um novo conhecimento, promovendo transformações em variados graus. Falamos, assim, de relações e de um processo permanente de constituição de si e, neste sentido, de uma áskesis. O si, contudo, não aponta para um ser unívoco, ou um ser-essência, cuja reflexividade própria ao pronome estivesse pré-determinada por uma imagem-mesma-de-si, narcísica, uma identidade a ser buscada como de frente a um espelho. A reflexividade do pronome 'si' aponta, pelo contrário, a um movimento circular de produção da existência, sempre em vias de se constituir. Implica olhar para o espelho sem buscar uma imagem definida de si, mas ver no reflexo o próprio processo da vida em conjunção com muitas outras vidas; este nos parece ser o processo que, encontrado por Foucault entre os antigos gregos, vemos também ser constituinte da prática do yoga.

Ser "sujeito de", "na relação com", advém de um movimento circular de produção de si, que instaura o "entre-dois" ali onde só haveria "um". (...) Há uma impossibilidade de ser sozinho e é essa a circularidade constituinte, o que somos nasce do "entre-dois", das relações com os outros seres, e retorna a essa condição produzindo uma sempre diferenciação. (CÉSAR, 2008, p. 61) 
O sujeito, nesta perspectiva, é entendido como o próprio processo de subjetivação, que se dá no encontro entre diferentes outros - principalmente, mas não só humanos - e que nunca cessa de produzir diferenças. Como vimos, numa sessão de prática de yoga, um sujeito é constantemente dessubjetivado de seu si conhecido, enquanto é atravessado por distintas linhas de sensação e percepção, de modo a constituir-se, a cada vez, um novo si. É impossível pensar a subjetividade sem este lugar do outro - um outro fluxo de ar, outro fluxo muscular, outra postura corporal, outra percepção, outro foco mental - que nos arranca permanentemente de nós mesmos, incitando a processualidade do ser. Portanto, este outro não está somente no plano das formas já definidas - um outro ser humano constituído, outro indivíduo -, mas também e principalmente, está em um plano intensivo, experimentado como uma nova suavidade (ROLNIK, 1994), um novo campo e corpo de forças com o qual se contata.

Vimos que uma prática corporal como a do yoga - ou deste yoga que ora propomos -, pode produzir deslocamentos ético-estéticos, abrindo o corpo do praticante a processos de transformação através de um reposicionamento sensível nas relações; neste sentido é que se torna uma forma de áskesis contemporânea. Se a prática é tomada como exercício de liberdade, significa que as novas relações não devem visar subjugar e nem exercer uma tirania sobre o outro, mas sim visar uma abertura à alteridade, a um processo de outramento, de perpétuo tornar-se. Tanto os estudos de Michel Foucault sobre os gregos quanto os estudos sobre o yoga nos auxiliam a pensar modos de efetivar este processo na vida.

O si advém em um movimento de liberdade e das relações com o mundo. Se há esvaziamento de um si fundamento é porque, paradoxalmente, o si, enquanto passagem e liberdade transborda em um exercício de "outramento", de alteridade, de transformação de si. É por poder libertar-se de si, abandonar-se como fundamento, neste gesto anti-narcísico ou anti-proprietário que a alteridade advém como valor supremo (CÉSAR, 2008, p. 66).

Esta abertura da subjetividade para a alteridade depende da capacidade de suportarmos um fato simples: de que não somos um corpo que funciona de maneira isolada, somos processos de constituição permanentes em uma teia de relações, como a própria prática do yoga mostra, ao iniciar-se com um deslocamento da conexão com o ar, com os sons e com a pulsação do corpo.

Abrir-se à dimensão das diferenças implica destituir o lugar de um 'eu' racional, controlador e tirânico, e suportar os movimentos de transformação sempre insistentes, que nos deslocam e nos reposicionam nas relações. Assim sendo, a alteridade como descrita aqui abre campo para pensarmos a constituição de um homem que deixa de se limitar ao vetor moral, enquanto conhecedor dos códigos, leis, valores e verdades da sociedade em que se vive, para pensarmos um homem que ativa um outro vetor, de alçada ética, cultivado a partir de uma prática preocupada em estabelecer uma nova relação consigo.

A nosso ver, enfim, o yoga pode ser considerado uma prática de si e uma áskesis, que nos coloca frente à alteridade de modo processual, lento e gradual e, talvez por isso, 
consistente. É dessa consistência, então, que nasce a verdade do yoga: uma verdade que pode ser desligada da universalidade e da eternidade, nascida da sinceridade com que se pratica e da coragem com que se volta o olhar para um si potencialmente outro.

\section{REFERÊNCIAS}

CÉSAR, Janaína Mariano. Processos grupais e o plano impessoal: a grupalidade fora do grupo. (Dissertação de mestrado) - Universidade Federal Fluminense, Rio de Janeiro, 2008.

DANIÉLOU, Alan. Shiva e Dionísio: a religião da natureza e do Eros. São Paulo: Martins Fontes, 1989.

FOUCAULT, Michel. A coragem da verdade. São Paulo: Martins Fontes, 2011.

FOUCAULT, Michel. A hermenêutica do sujeito. 2 ed. São Paulo: Martins Fontes, 2006.

HADOT, Pierre. O que é a Filosofia Antiga?São Paulo: Ed. Loyola, 1999

MISHRA, Kamalakar. Kashmir Saivism: the central philosophy of tantrism. Varanasi: Indica Books, 2011.

ROLNIK, Suely. Cidadania e alteridade: o psicólogo, o homem da ética e a reinvenção da democracia. In: SPINK, Mary Jane P. (org.). A cidadania em construção. São Paulo: Cortez, 1994.

SARASWATI, Swami Satyananda. A sistematic course in the ancient tantric techniques of yoga and kriya. Bihar: Yoga Publications Trust, 2013.

SARASWATI, Swami Satyananda. Four chapters on freedom: commentary on the yoga sutras of Patanjali. New Delhi: Yoga Publications Trust, 2008.

SARASWATI, Swami Satyananda. Kundalini Tantra. Bihar: Yoga Publications Trust, 2007.

SARASWATI, Swami Satyananda. Taming the kundalini. Bihar: Yoga Publications Trust, 2009.

SARASWATI, Swami Satyasangananda. Karma Sannyasa. Bihar: Yoga Publications Trust, 2006.

SINGLETON, Mark. Yoga Body: the origins of modern posture practice. Nova lorque: Oxford University Press, 2010.

Recebido em: Maio/2017

Aprovado em: Agosto/2017 